\title{
Finite element analysis and microscopy of natural fiber composites containing microcellular voids
}

William T. Kern ${ }^{\text {a }}$, Wonsuk Kim ${ }^{\text {a, }}$, Alan Argento ${ }^{\text {a }}$, Ellen C. Lee ${ }^{\text {b }}$, Deborah F. Mielewski ${ }^{\text {b }}$

${ }^{a}$ Department of Mechanical Engineering, University of Michigan-Dearborn, 4901 Evergreen Road, Dearborn, MI 48128, USA

${ }^{\mathrm{b}}$ Materials Research and Advanced Engineering Department, Research and Innovation Center, Ford Motor Company, 2101 Village Road, Dearborn, MI 48124, USA

* Corresponding Author:

Wonsuk Kim, Ph.D.

Department of Mechanical Engineering, University of Michigan-Dearborn, 4901 Evergreen Rd., Dearborn, MI 48128, USA

E-mail: wskim@umich.edu, Tel: +1-313-436-9164 


\begin{abstract}
Mechanical behaviors of chopped, natural fiber composites with and without closed-cell microcellular foamed structures are investigated using finite element analysis (FEA), with references to previously conducted experimental measurements of the stress-strain characteristics of analogous test specimens and their microscopic images. Analytical and FEA models are compared for a simple, aligned fiber case; the FEA models are then extended to composites having more general fiber arrangements. These FEA results are compared to experimental stressstrain data. Scanning electron microscopy (SEM) images of fracture surfaces from test specimens are analyzed, and correlations between numerically predicted behaviors and fracture paths, and fracture surface images are discussed. The FEA results reflect experimental trends well including the effects of fibers and the presence of voids. These have also been found to induce specific regions of stress concentration. Inspection of fracture surfaces reveals transition from ductile to brittle behavior at low strain rates, generally brittle failure modes, and little evidence of fibers stressed to their tensile limits.
\end{abstract}

\title{
Keywords:
}

Finite element analysis, scanning electron microscopy, natural fiber composite, microcellular foamed structure, wheat straw

\section{Introduction}

Injection molded, chopped-fiber composites are of interest in manufacturing as an expedient and low-cost means of tailoring the properties of structural plastics. Glass fibers have traditionally been used as the reinforcing material in injection molded structures, but more recently, interest in supplanting glass with natural fibers has increased. Though natural fibers are generally less stiff than glass fibers, they offer advantages in cost, noise attenuation, recyclability, disposal, carbon footprint, and worker exposure hazard [1-6]. Because they are not a manufactured product, natural fibers possess a wide variety of variability including length, aspect ratio, surface condition, and elastic properties, making it important to establish methods for predicting behavior of polymeric composites made from them. Static macrostructural properties of chopped-fiber composites have been studied extensively [7-15]. Properties of natural fiber composites have received less study in this regard [1-3, 5, 16-22], and little research 
exists that investigates the microstructural behaviors of these composites [18, 23-31]. This is particularly true for the fiber in the current study, wheat straw [32], that is typically thicker and shorter than more-commonly used natural fibers such as jute. Microstructural voids added by gas-foaming in the mold $[18,23-25,27,28,33,34]$ offer a potential element of commercial value, but also add complexity in modeling.

In the present work, numerical FEA methods are used to explore the stress fields within the matrix and fibers, and along the fiber-to-matrix interface. Four lengths of fiber are separately considered in models having either solid or voided structure, the latter simulating a microcellular foam. Aligned-fiber FEA models are compared to analytical methods, then extended to nonaligned-fibers and microcellular structures. These models are configured to the geometric and elastic properties of wheat straw fiber and polypropylene (PP), and the predicted properties of the composites are compared to experimental data.

The findings show that fibers tend to produce stress concentrations at their tips, especially when they are aligned with the loading directions. Voids tend to result in stress concentrations on their material surface at points furthest from the axis of the loading direction. The interaction of these effects produces a structure that previous experiments by the present authors have shown to be stiffer and more brittle than pure PP, but with very little change in ultimate tensile strength [32]. The addition of microcells reduces overall stress levels at all strains by redistributing microstructural stress fields.

\section{Finite element modeling}

Models were built to investigate the properties of polypropylene plastic reinforced with short, arbitrarily-distributed fibers. Mechanical and geometric properties were chosen to simulate an inedible by-product of wheat straw fiber and Basell Pro-fax 6523 polypropylene homopolymer.

The structure of the modeled composite can be seen in Fig. 1. All specimens contain wheat straw fibers in the volumetric fraction of approximately $10 \%$ that are evenly distributed throughout the structure. The volumetric fraction of fibers was calculated from the known density values of PP and wheat straw fiber, and fiber mass fraction of $20 \%$ [2]. Here, foaming reduces the mass of the specimens by $10 \%$ in most cases, but cells tend not to form in a skin region along the outer surfaces, as is typical [35], and is probably due to dissolved gas diffusion into the core prior to bubble formation. Microcells are generally $25-50 \mu \mathrm{m}$ in diameter. Process 
optimization is required to avoid formation of long, thin gas pockets which can form just inside the skin.

On the basis of available research [36-39] and SEM observations from the current study, the geometric parameters listed in Table 1 were used in the models. The fiber lengths of 167 and $333 \mu \mathrm{m}$ were selected from the typical short fiber specimens, and the 667 and $1000 \mu \mathrm{m}$ lengths were determined from the typical long fiber specimens, manufactured and tested in [32].

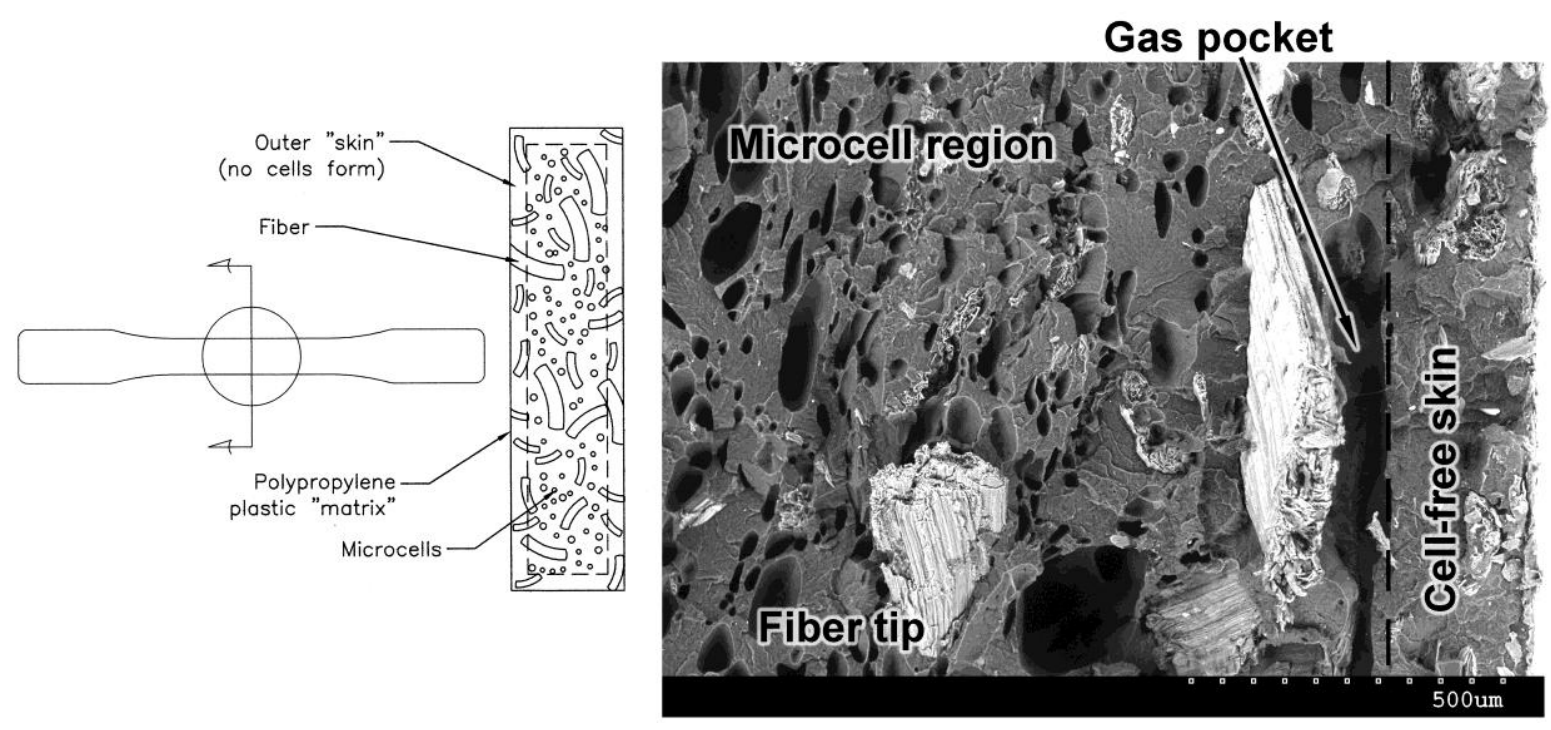

Fig. 1. Topography of a wheat straw specimen with microcellular structure. Fibers and cells in schematic at left are larger than true scale. At right is an SEM image of the fracture surface of a tested specimen (ASTM D638 Type I) showing a typical microstructure. The skin region tends to be free of voids. Void concentration increases away from the skin.

Table 1 Sizes and proportions of composite features

\begin{tabular}{lcc}
\hline Component & Actual size $(\mu \mathrm{m})$ & $\begin{array}{l}\text { Size normalized } \\
\text { to cell diameter }\end{array}$ \\
\hline \hline Overall width & 12,700 & 254.0 \\
\hline Overall thickness & 3,100 & 62.0 \\
\hline Skin thickness & 450 & 9.0 \\
\hline Fiber diameter & 100 & 2.0 \\
\hline & 1,000 & 20.0 \\
Fiber length cases & 667 & 13.3 \\
& 333 & 6.7 \\
\hline Cell diameter & 167 & 3.3 \\
\hline
\end{tabular}




\subsection{Construction of the finite element models}

Except for a few special test cases, all FEA models represent the gauge section of ASTM D638 Type I test pieces. Models were constructed in AutoCAD 2013 as unit-thickness 3D solids, imported into Abaqus. All models, except as noted, were seeded with a global seed value of 20 $\mu \mathrm{m}$, and meshed with elements of wedge type C3D6. In Figs. 12 and 13, this resulted in 26,398 elements in the fibers, 233,764 elements in the solid, and 228,374 elements in the microcellular matrices. The focus of this study is the in-plane response of the composites, such as in an axial loading test for characterization of the composites. As such, all loads are applied in-plane and the in-plane stresses are described. The matrix was configured in Abaqus using the second-order polynomial strain energy potential model. For non-aligned-fiber solid models, the matrix was first constructed as a CAD solid part. Then, for each tested fiber length, a set of $n$ fibers was constructed, where $n$ was the number of individual fibers needed to produce the correct volumetric fiber content. These fibers were then assigned in-plane orientation angles of $0,15,30$, $45 \ldots 165$ degrees, with equal numbers of fibers at each orientation. Then these fibers were arbitrarily distributed into the matrix. The volumetric envelope of the fibers was subtracted from the matrix volume, leaving voids for the solid fibers to occupy. The matrix and fiber models were imported into Abaqus, and a "tie constraint," permitting no relative movement at the boundary, was defined between the matrix and fibers, with the matrix as "master" surface. Thus, interfacial damage and de-bonding features are not included in the present model. These features have begun to receive treatment for natural fiber (hemp) composites using a specialized single fiber composite for FEA models and experiments [40]. Knowing the failure mechanisms and strengths of wheat-straw composites, the models developed in the present manuscript could be extended to estimate the bond failure by generalizing the interfacial modeling. It should also be noted that the arbitrary fiber distribution mentioned above is not guaranteed to be mathematically random such as that in [41]. However, to confirm that the distribution of fibers here does not texture the results, each model was loaded in the $\mathrm{X}$ direction, then the $\mathrm{Y}$ direction, resulting in nearly identical stress/strain behavior in each case. Fig. 2 shows a portion of the matrix, with fibers having 0,60 and 105 degree orientations identified. 


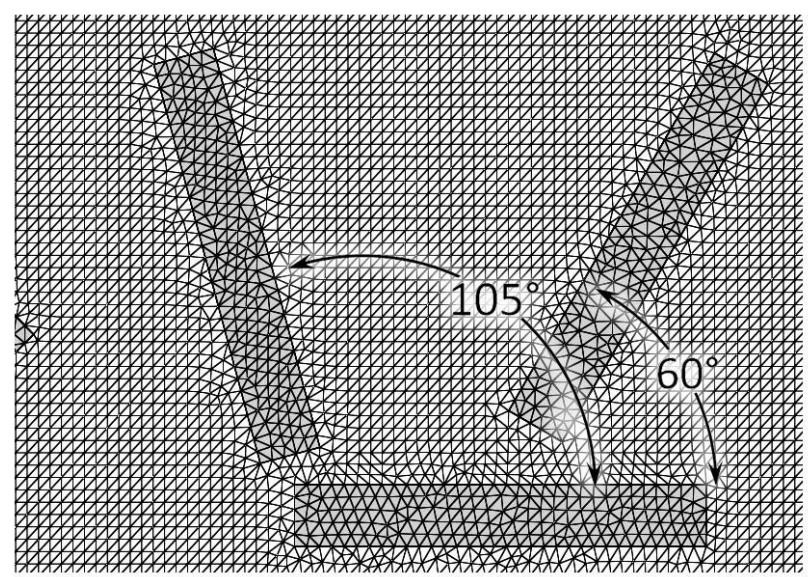

(a)

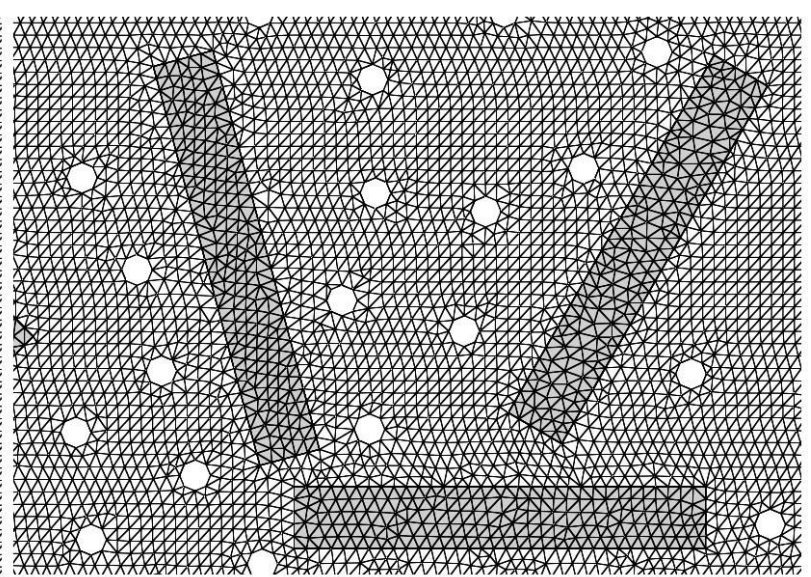

(b)

Fig. 2. Portion of FEA mesh of arbitrarily distributed wheat straw fibers embedded in (a) solid and (b) microcellular polypropylene matrix used for general models, with some discreet fiber angles shown.

For microcellular models, the process was the same, except that after subtracting the fibers from the matrix, a predetermined count of circles, $50 \mu \mathrm{m}$ in diameter, was arbitrarily distributed in and subtracted from the remaining solid of the matrix model. Solid and microcell models of a given fiber length had identical fiber components. All models had the same volumetric proportion of fibers, and the same volumetric proportion, size and count of microcells. Wheat straw fiber properties were taken from typical data presented in published literature. In references [36] and [37], a tensile modulus range of 2.8-7.9 GPa and strength range of 49.5146.3 MPa were measured at room temperature, depending on fiber preparation and test conditions. For the numerical results presented here, moderate values of $6 \mathrm{GPa}$ and $100 \mathrm{MPa}$ were used for tensile modulus and strength, respectively. The nonlinear constitutive behavior of the PP matrix material was determined from preliminary tests on neat PP samples. The overall model consists of a free end to which uniform pressure is applied, and a fixed end that is fully constrained (no point on the end surface may move in any direction). To prevent distortion of the end surface, the free end is tie-constrained to a rigid body constrained against rotation about any coordinate axis. This modeling strategy produces identically controlled ends with a true loadcontrolled stress condition. Fig. 2 shows the FEA mesh for the non-aligned-fiber cases. Cases with all fibers aligned with the load directions (aligned-fiber models) are similar to Fig. 2. 


\subsection{Validation of the FEA model}

A single-aligned-fiber model was constructed to allow direct comparison of the FEA models and analytical methods available in published research [7, 42]. Geometry and elastic moduli of fibers and matrix were selected to match the dimensionless parameters in [42]. For the singlealigned-fiber FEA validation model, a symmetrical single-quadrant model was used for computational efficiency at very high mesh resolution. Note that in all cases where FEA models were intended for direct comparison to analytical methods, the matrix was necessarily defined as linear elastic.

The aligned-fiber FEA model was convergence-tested by applying increasingly fine mesh to the model to confirm convergence to a value of stress. Fig. 3 shows the axial stress, $\mathrm{S}_{11}$, calculated along the centerline of a fiber, and in the matrix between fiber tips. Stresses are seen to converge to the solid black line as element size is reduced. In this case, peak stress changes by $0.35 \%$ from $40 \mu \mathrm{m}$ to $32 \mu \mathrm{m}$ elements. Elements of size $40 \mu \mathrm{m}$ were used everywhere other than non-critical regions of the model where stress and deformation variations were small, where 70 $\mu \mathrm{m}$ elements were used. For the non-aligned-fiber models shown in Fig. 2, approximately $20 \mu \mathrm{m}$ elements were used.

Fig. 4 compares the present FEA results to analytical and experimental results in [42]. The FEA centerline stress compares well to the previously published results.

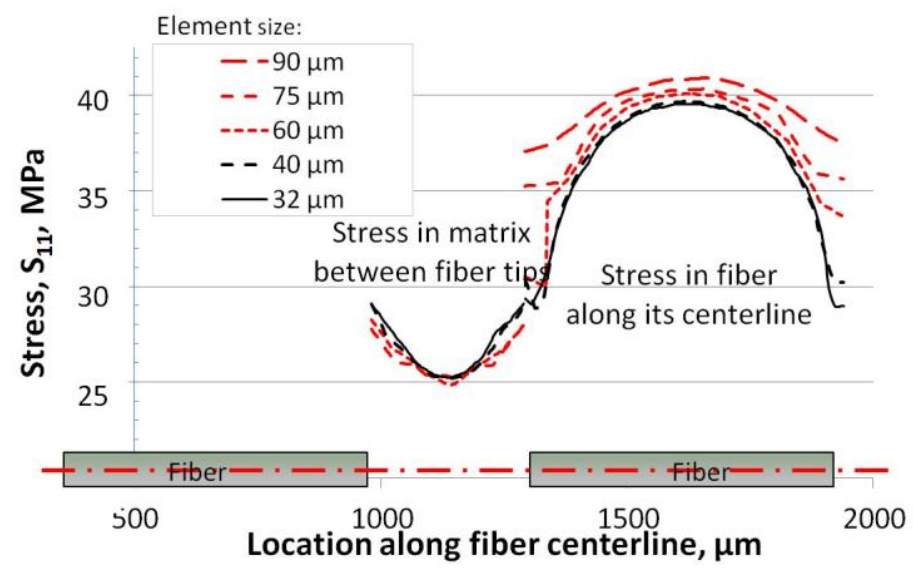

Fig. 3. Convergence of FEA model with increasing mesh density. 


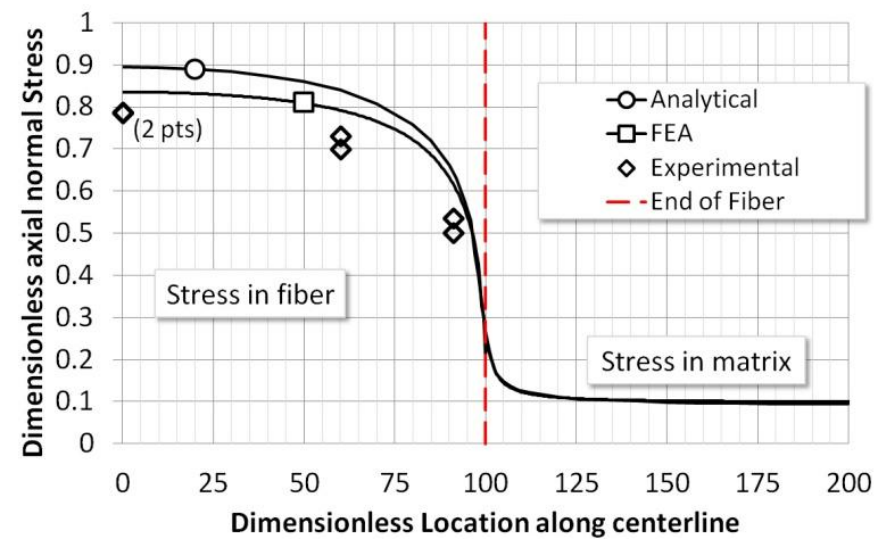

Fig. 4. Dimensionless centerline axial stress in fiber and matrix by analytical [42], numerical (FEA), and experimental [42] methods.

The non-aligned-fiber model was first validated using an equation in [7] for the estimation of non-aligned-fiber composite mechanical properties, when tensile properties are known for an aligned-fiber composite with the same proportion of fiber content. Equation (1) gives Young's modulus for a non-aligned-fiber composite in terms of the moduli along and perpendicular to fibers of an otherwise identical aligned fiber composite [7].

$$
E_{(\text {non-aligned })}=\frac{3}{8} E_{(\text {along fibers })}+\frac{5}{8} E_{(\text {across fibers })}
$$

Aligned-fiber FEA models were constructed and moduli extracted along and across the fibers using the stress-strain response. Another FEA model, with the same fiber fraction but nonaligned orientation, was constructed and moduli extracted along and across its length using the initial slope of the overall stress-strain response, similar to what would be obtained in a physical stress-strain test. Table 2 shows that the two moduli values from the non-aligned FEA model are within $1 \%$ of each other, indicating that the arbitrary distribution process used here is acceptable since it does not produce textured response. Also, the average $(1.321 \mathrm{GPa})$ of these two values agrees within $0.6 \%$ with the value based on Equation (1). 
Table 2 Young's modulus predicted for random-fiber composites by analytical and FEA models. Fiber length is $667 \mu \mathrm{m}$, and the matrix is modeled as linear elastic with E=1.1 GPa.

\begin{tabular}{ccccc}
\hline \multicolumn{2}{c}{ Aligned-fiber FEA } & \multicolumn{2}{c}{ Non-aligned-fiber FEA } & \multirow{2}{*}{$\begin{array}{c}\text { Non-aligned-fiber } \\
\text { Equation (1) }\end{array}$} \\
\cline { 1 - 3 } Along fibers & Across fibers & Along length & Across length & $1.328 \mathrm{GPa}$ \\
\hline $1.433 \mathrm{GPa}$ & $1.265 \mathrm{GPa}$ & $1.317 \mathrm{GPa}$ & $1.325 \mathrm{GPa}$ & $1.328{ }^{2}$ \\
\hline
\end{tabular}

\section{FEA results}

\subsection{Stress fields in aligned-fiber models}

Fig. 5 shows the axial stresses $\left(\mathrm{S}_{11}\right)$ which occur in aligned-fiber FEA composites with linear-elastic matrices along the centerline of a row of fibers for two fiber lengths, $1000 \mu \mathrm{m}$ and $667 \mu \mathrm{m}$, that correspond to length-to-diameter aspect ratios of 10/1 and 6.67/1, respectively. In the graph, curves above the dashed line are the stresses in the fibers and stresses below the dashed line are the stresses in the matrix "ligament" between the fibers. The peak axial stress in the fiber in the longer fiber case is seen to be 1.39 times higher than that in the shorter fiber case (72.7 MPa vs. 58.4 MPa) when the stress of $30 \mathrm{MPa}$ is applied. The peak axial stress in the matrix ligament is less affected by fiber length than the stress in the fiber, though the variation in stress across the ligament is greater in the long fiber case. Specifically, the stress in the matrix ligament varies from 21 to $33 \mathrm{MPa}$ in the long fiber case, and from 29 to $35 \mathrm{MPa}$ in the shorter fiber case. More-realistic FEA models with nonlinear matrices and limited tensile strength will not reach these stress levels. 


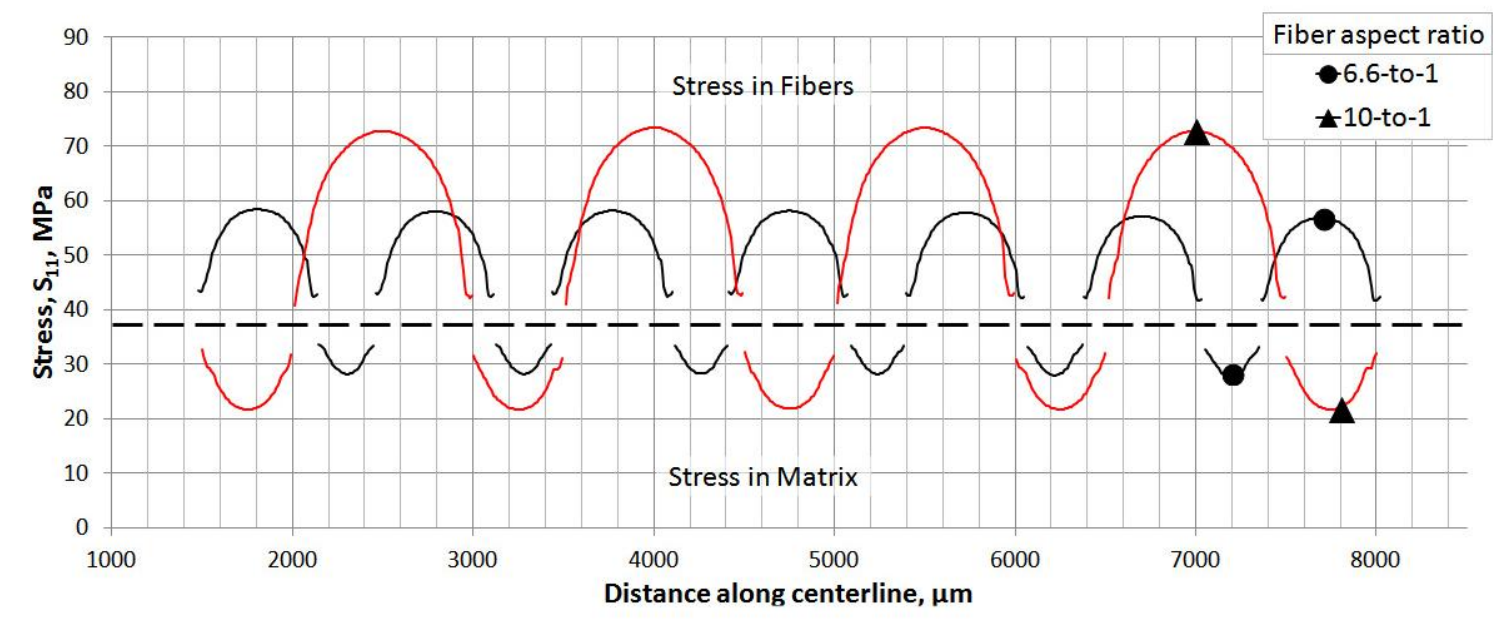

Fig. 5. Axial stress in fibers and matrix along longitudinal centerline of a portion of a fiber row in aligned fiber composites.

Fig. 6 illustrates the stress variation in the matrix of an aligned-fiber model in terms of the axial and transverse locations. The von Mises stress is plotted along a series of horizontal lines (1)-(5) shown in Fig. 6(b). Line (1) is at the midpoint between the adjacent rows of fibers and line (5) is along the lower, or near, fiber-matrix interface. Thus, each of the curves in Fig. 6(a) describes the variation in von Mises stress in the matrix along the axial direction. Comparing the curves shows the variation of stress in the matrix moving away from the near fibers up to the midpoint between the near and distant fibers. Curves (1)-(5) show, in general, the matrix stress varies greatly along the axial direction and is strongly influenced by the near fibers. Curve (5), along the interface, shows the greatest variation in stress and has the greatest overall stress, while curve (1) at the midpoint between the near and distant fibers is seen to have the lowest peak stress and least variation in stress. Along curves (2)-(5), stress is seen to be lowest in the near fiber regions and to increase in the ligaments between the fibers. For curves nearer to the fibers, the stress increase in the ligament region is pronounced. In general, stress in the near fiber region increases away from the fiber toward the centerline, while stress in the ligament region decreases toward the centerline. The fiber length and end-to-end spacing may have a complex interaction as seen later in Fig. 11. 


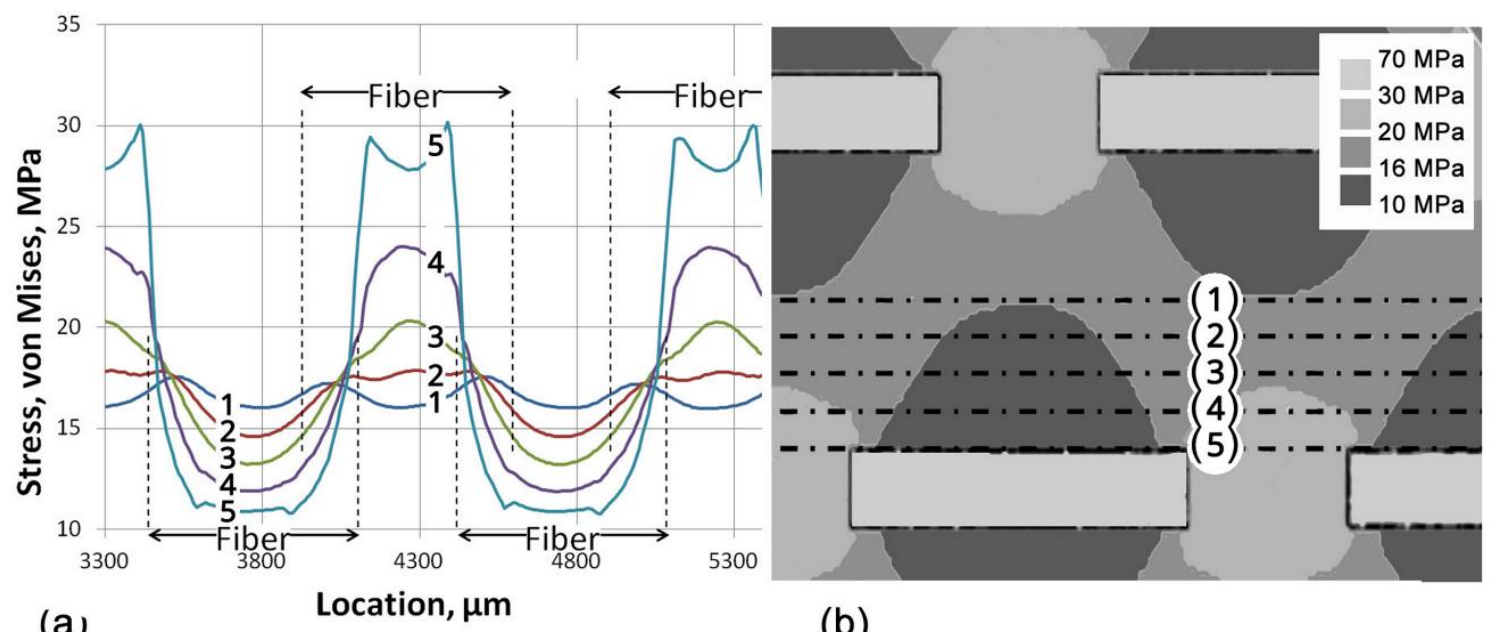

(a)

Location, $\mu \mathrm{m}$

(b)

Fig. 6. Stress field (von Mises) in matrix between fiber rows of an aligned-fiber composite model of fiber length $667 \mu \mathrm{m}$. Loads are applied to the model along the fiber direction. Curves 15 in (a) indicate stresses taken from the FEA model along lines (1)-(5) in the whole field stress map, (b). Darker regions in (b) indicate lower stress.

Fig. 7 shows the in-plane shear stress $S_{12}$ in the matrix generated along the fiber/matrix interface line. Though these stresses are relatively small, they contribute to fiber pull-out failures, where intact fibers separate from the matrix. Note that "crack-bridging" theories appropriate for composites with much longer fibers do not apply [9, 43].

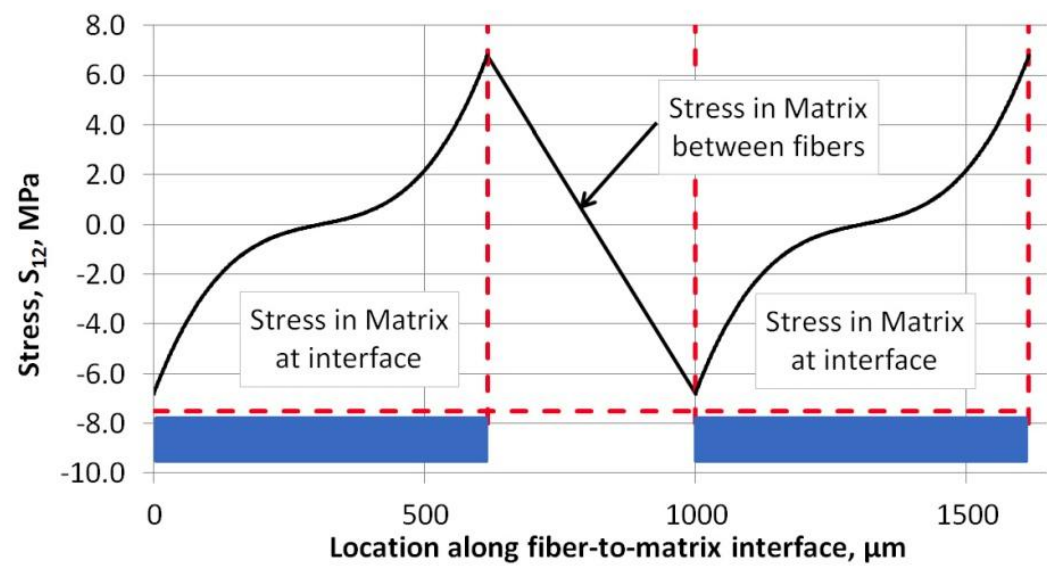

Fig. 7. Shear stress $\left(S_{12}\right)$ in matrix along fiber/matrix interface line. Loads are applied to the model along the fiber direction. 


\subsection{Non-aligned-fiber models}

Non-aligned-fiber models with various lengths of fibers have been constructed. Here, as shown in Fig. 8, the net stress-strain curves of the composites are determined from the FEA models and compared to experimental results in [32]. The FEA curves are well matched in general to the experiments in both solid (Fig. 8(a)) and microcellular (Fig. 8(b)) cases although the FEA results slightly under-predict the influence of fiber length.

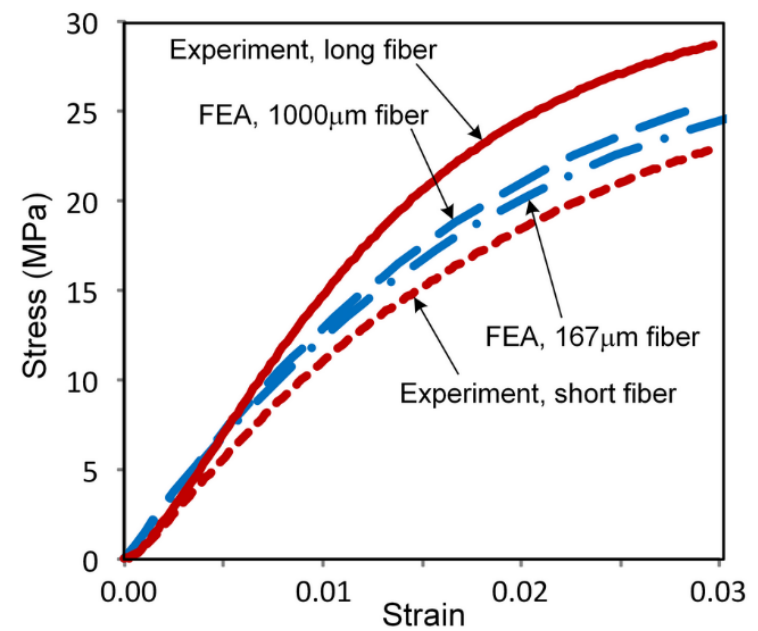

(a)

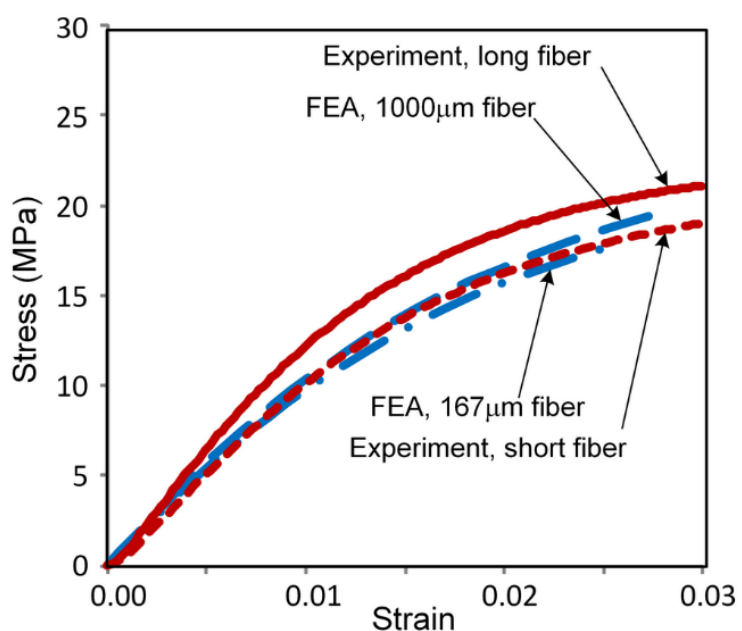

(b)

Fig. 8. Stress-strain curves of non-aligned-fiber composites (a) without and (b) with $10 \%$ microcells. The lengths of long and short fibers in experimental specimens are approximately 650-1000 $\mu \mathrm{m}$ and 150-300 $\mu \mathrm{m}$, respectively.

Next, the effect of fiber length on stress levels within fibers is explored. Fig. 9 gives the maximum axial stress $\left(S_{11}\right)$ experienced at the centerline of fibers which are aligned with the applied stress. This is regarded as the best predictor of fiber failure, because if so-selected fibers do not reach a failure stress level, then no fibers in the composite will fail in simple tension. Analytical methods [7] have shown that as the fiber length increases in solid, aligned-fiber composites, the composite modulus and fiber stresses increase nonlinearly, approaching those values of a continuous-fiber composite of the same fiber volumetric fraction. The similar trend of increasing fiber stress with length is seen in the non-aligned-fiber cases as well as the aligned fiber case in Fig. 9. However, even when applied stress increases to failure levels, fiber stresses rarely approach the $100 \mathrm{MPa}$ ultimate tensile strength of the fiber [36, 37] in all FEA models 
treated here. As a result, very few fibers are expected to fail in simple tension, and this result is strongly confirmed by SEM inspection of experimental specimens. Another aspect observed in Fig. 9 is that the fiber stress values of the non-aligned-fiber models are higher than those of the aligned-fiber models, as expected, except when the fiber length is $167 \mu \mathrm{m}$. The aligned-fiber models are included for continuity of the discussion, but since the primary interest here is the more practical non-aligned-fiber composites, the difference at the shortest fiber length has not been investigated further. It is also seen in Fig. 9 that the fiber stress increases due to the presence of microcells.

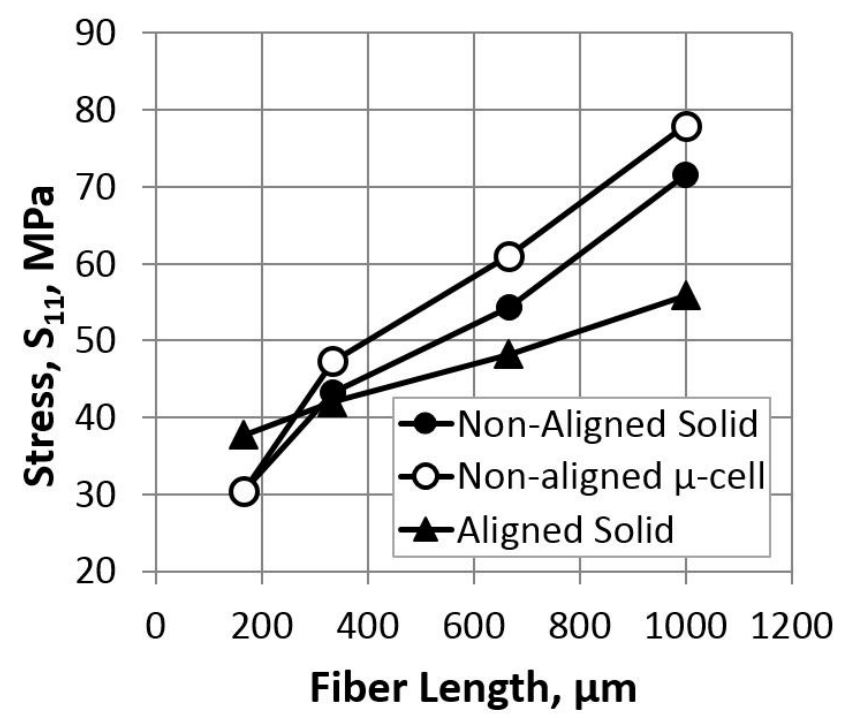

Fig. 9. Effect of fiber length on the maximum centerline axial stress $\left(S_{11}\right)$ in fibers when applied stress is $18 \mathrm{MPa}$. Models are solid or 10\% microcellular void fraction, $10 \%$ volumetric fiber fraction.

\subsection{Microcellular effects}

To study the general effect of microcells, a 3-dimensional FEA model was created. Fig. 10 shows a cutaway view of a solid block with spherical voids representing microcells. Fig. 10(a) shows the stress field and Fig. 10(b) shows the variation of stress around the deformed ovular circumference. Stress is seen to be maximized at points on the oval furthest from the axis of the load direction (the horizontal direction) through the center of the void. 


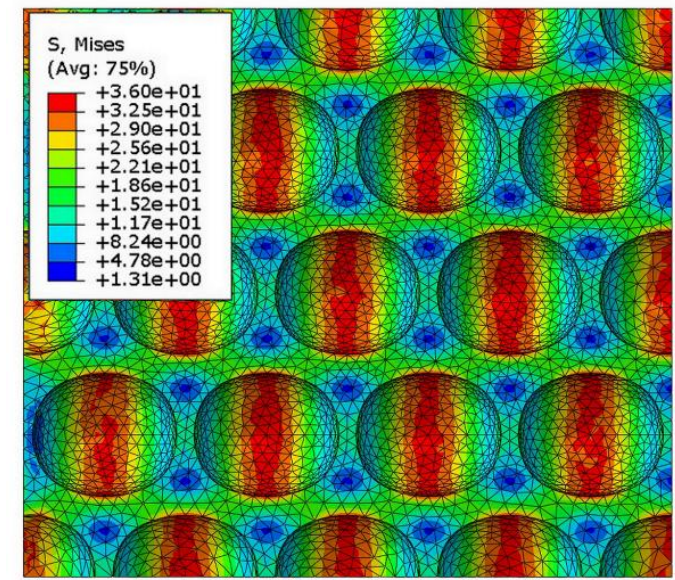

(a)

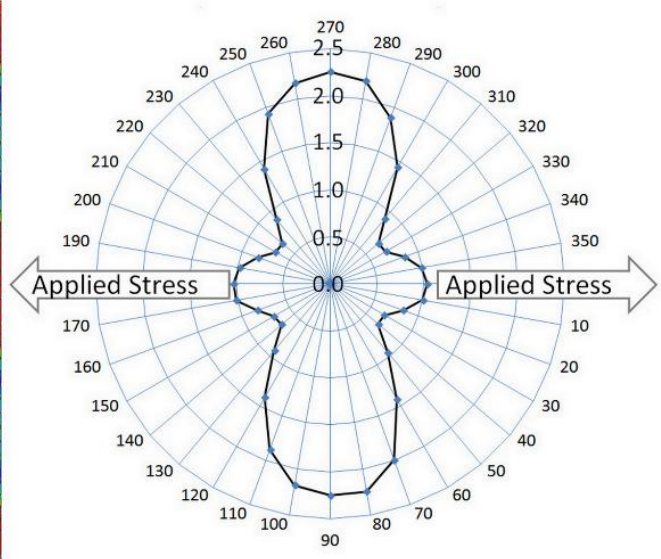

(b)

Fig. 10. (a) Cutaway view of 3D FEA model, showing stress concentration in microcells with applied stress of $15 \mathrm{MPa}$. Stress is applied in the horizontal direction in the plane of the image. (b) Polar plot indicating stress as a multiple of applied stress around $360^{\circ}$ of ovular cell periphery.

The stress gradient induced in the matrix by the voids is explored further in Fig. 11. Here a model with various features illustrates the stress fields in inter-fiber matrix ligaments in the aligned fiber case. Various ligaments in the model contain no microcells, one microcell and two microcells. If no microcells exist between fiber tips, as in the top row of fibers in Fig. 11(b), then the possible stress patterns that typically develop in the ligament are illustrated in curves (1) and (2) in Fig. 11(a), where the exact shape is determined by a complex interaction between fiber length, fiber aspect ratio, elastic moduli of matrix and fibers, and fiber axial spacing. In the cases shown in curves (3) and (4), where one or two microcells exist between fiber tips, stress fields in the ligament can vary greatly within the ligament depending on the number of microcells present. Peak stress is typically higher, and minimum stress lower, than in the ligaments without microcells. In the bottom fiber row of Fig. 11(b), the maximum stresses occur on vertical lines through the microcell centers, at the microcell boundary, as also seen in the more basic model, Fig. 10. In the single-microcell ligament, the peak stress reaches $300 \%$ of the externally-applied stress; the two-microcell ligament is slightly lower at $280 \%$. In comparison, the maximum stresses in the cell-free ligaments peaked at about $150 \%$ of the externally-applied stress. In both the solid and microcellular regions, the stress fields predicted in the ligaments show strong 
similarity to the cardioid "fan zones" describing damage levels in the study of fracture mechanics [44].

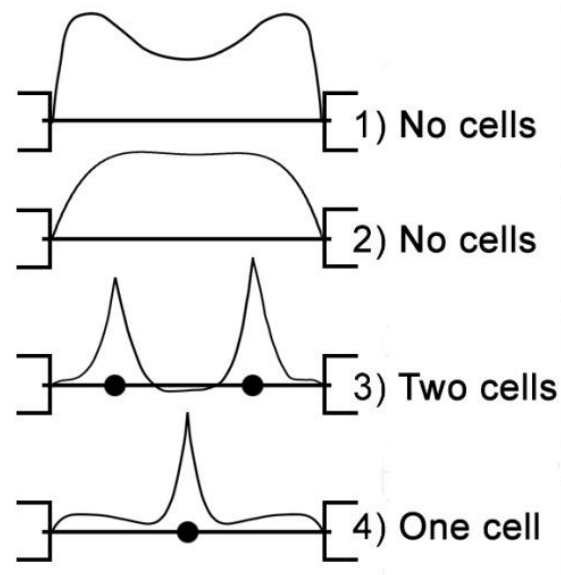

(a)

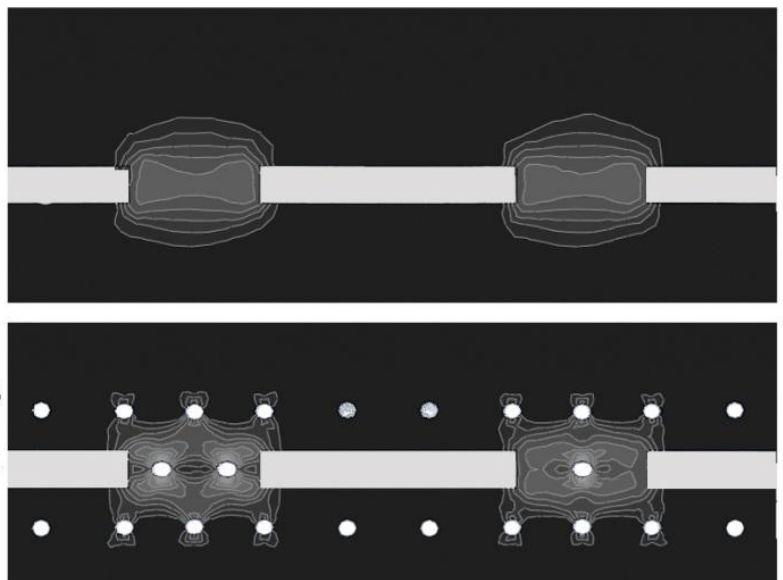

(b)

Fig. 11. Model having various composite features to illustrate the effects of microcells on aligned fiber model stress field. White bars are fibers and white circles are microcellular voids. (a) Stress amplitudes (von Mises) in ligaments between fiber ends; (b) FEA-predicted stresses. Lines are contours of constant stress. Darker shading indicates lower stress.

Figs. 12(a) and (b) give the stress distributions in typical regions of non-aligned-fiber solid and microcell models, respectively, when $20 \mathrm{MPa}$ stress is applied in the in-plane horizontal direction. Here, the two darkest regions indicate low stresses which are very unlikely to originate a fracture; the next lightest region indicates stresses which are approaching the critical stress level of the matrix where a fracture may occur; and the lightest region indicates a stress level where failure of the matrix is likely. For this particular example, the critical stress level for the matrix is considered to be $24 \mathrm{MPa}$ [32], and $100 \mathrm{MPa}$ for the fiber [36, 37]. Fibers often show white stresses, indicating their stress is higher than the stresses in much of the surrounding matrix, though the stress level does not approach the fibers' ultimate tensile strength. It is seen that when fibers are close together, and especially when closely aligned with the applied stress, as at point $\mathrm{P}$ in Fig. 12(a), increased stress occurs in the matrix between the fiber tips. As seen previously in the aligned fiber composite, microcells in Fig. 12(b) also create increased stresses in the matrix in their vicinity. Large areas of high stress occur where fiber tips align and contain 
a void in the resulting ligament, as at Point Q. Figs. 13(a) and (b) show that microcells enable greater localized strain in the matrix, which could be elastic or plastic in nature. This produces a small reduction in stress near the fiber ends, at the cost of having many more elevated-stress points around the microcells. The net effect is a softer stress-strain curve, confirmed in Fig. 8. High-stress points in the matrix could become fracture origins where an energy-releasing fracture process would start [44]. Fewer potential points of fracture origin exist in the solid structure than in the microcellular. Failure is also related to the tendency of a fracture initiation to propagate. In the solid FEA model of Fig. 12(a), large regions of non-critical stress (black or dark gray) exist all around the fibers, except where fiber tips, or fibers in close proximity, cause local regions of higher stress. In the microcellular model, Fig. 12(b), no such regions exist. This suggests the possibility of a shorter fracture path in the microcellular composites compared to the solid composites. Lastly, results not given here show that in the microcell case, the cell-free skin is at a slightly higher general stress level than an otherwise identical solid specimen, but the microcells do not otherwise affect the stress patterns in this region.

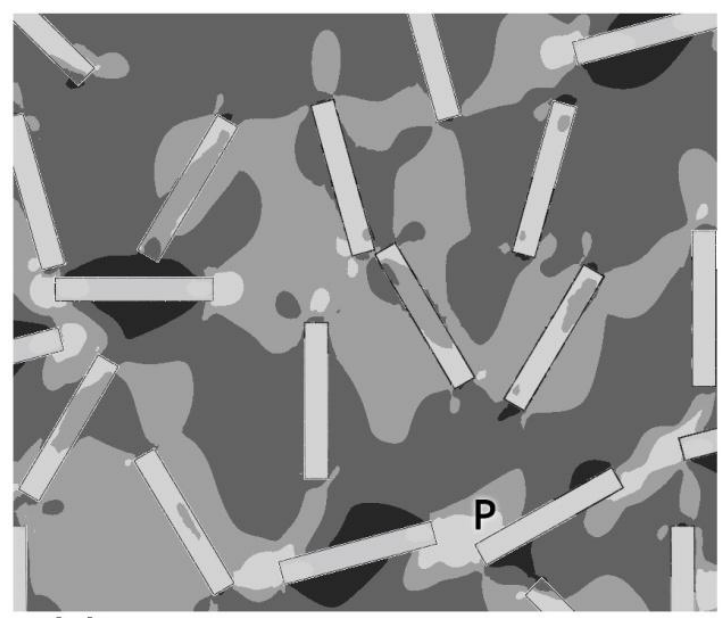

(a)

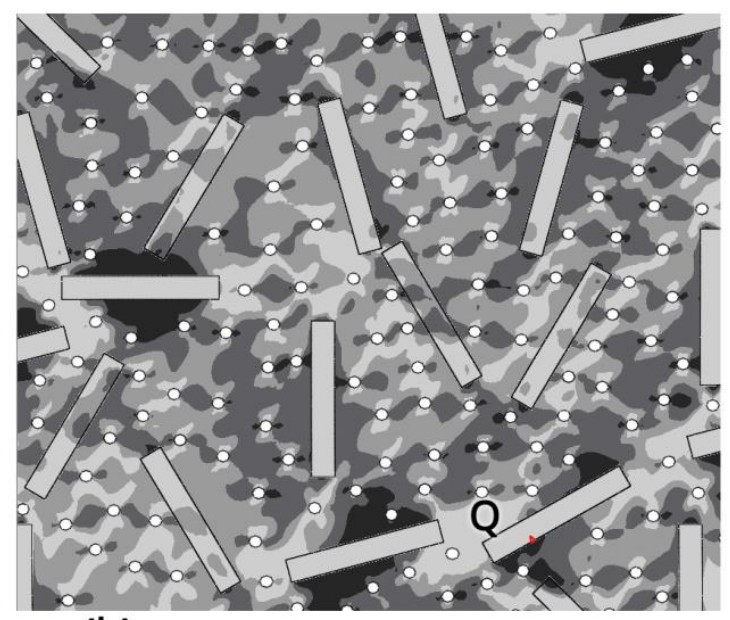

(b)

Fig. 12. von Mises stress distribution in typical regions of (a) solid and (b) microcellular models. Rectangles are $667 \mu \mathrm{m}$ fibers (10\% volumetric fraction) and white circles are microcellular voids (5\% volumetric fraction). White regions in the matrix material indicate stresses above failure levels of the plastic. 


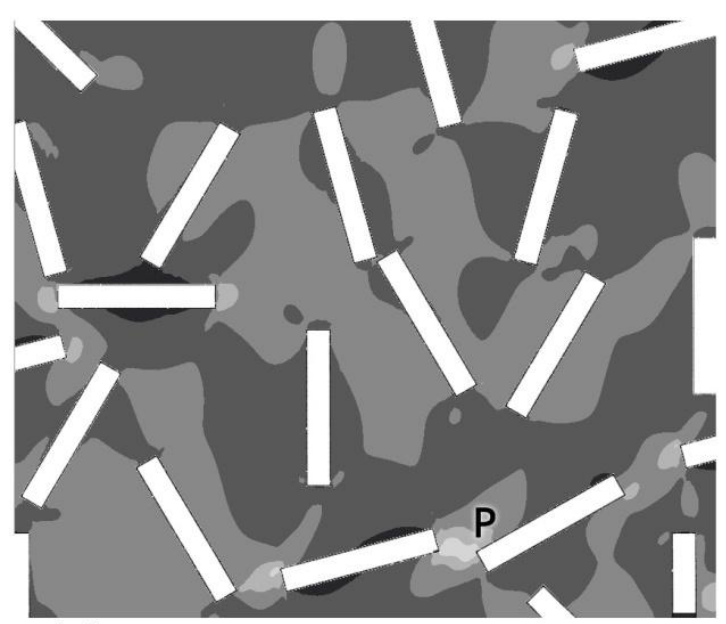

(a)

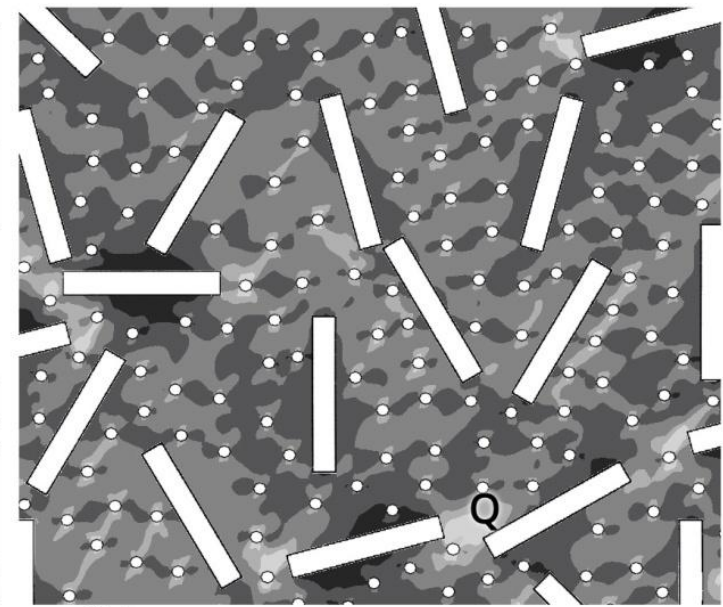

(b)

Fig. 13. Strain fields in matrix for composites of Fig. 12: (a) solid and (b) microcellular models. White color of fibers does not represent strain level.

\section{Microscopic observations and analysis}

While several modes of failure are seen on any given fracture surface, in particular, two predominant modes occur: "Fiber pull-out" and "grazing" failures. In solid specimens, and in the solid regions of microcellular specimens, fiber stubs are found to protrude a length of one to three fiber diameters from the fracture surface. These are commonly referred to as "pull-out failures" [7, 9], and are caused by failure of the fiber-to-matrix interface. Fiber pull-out can be seen in the solid portion of Fig. 1 near the skin. In the microcellular regions of microcellular specimens, very few fiber pull-out failures are seen. Instead, the matrix tends to fracture through the microcells, leaving a flat surface with small points of exposed fiber in a so-called "grazing fracture" [45], or leaving the fiber entirely buried just below the fracture surface. Here, grazing fractures have been found to predominate in microcellular regions, and remain consistent in appearance over a wide range of strain rates. In Fig. 1, grazing fractures are indicated by the small white flecks of fibers in the microcellular region of the microstructure. This should be contrasted with the large fiber portions that remain after pull-out failure. Unlike monolithic solids, which commonly fail when an internal or surface flaw acts as a fracture origin [46, 47], fracture in the composites studied here appears to start at many interior points. In no case has a single fracture origin been apparent on a fracture surface, and no discernible fracture patterns 
have been found to indicate an orderly or progressive fracture, as would be seen, for example, in glass [46].

Fig. 14(a) shows the failure surface of a solid structure, short-fiber tensile test specimen at a very low strain rate of $0.0005 / \mathrm{s}$, and room temperature of $22^{\circ} \mathrm{C}$. The tests that produced the SEM images given here are described in [32]. In this case, the plastic displays ductility indicated by the long strands of elongated plastic and flowing appearance. This specimen broke at $4.9 \%$ strain and $25 \mathrm{MPa}$ failure stress. Fig. 14(b) shows the same type of specimen, also at $22^{\circ} \mathrm{C}$, tested at $0.025 / \mathrm{s}$, which is a 50 times higher strain rate but still considered a quasi-static rate of strain. This specimen had a failure strain of $4.2 \%$ and failure stress of $30 \mathrm{MPa}$. The fracture is entirely brittle, indicated by the flat, scale-like appearance of the fracture surface and the presence of cracks. Despite the differences in the state of the plastic (ductile or brittle) in these two figures, stubs of fiber protrude from the fracture surface a length equal to about 1 to 3 diameters in both cases, and failures occurred at similar strains and stresses. While testing and microscopy of wheat straw composites are scarce, other researchers [48-51] working with similar natural fibers, predominantly jute, hemp, and sisal, give SEM images showing brittle fracture of the matrix at very low strain rates, and with protruding fiber tips very similar to that of the present work. Given that in Figs. 14 (a) and (b) the plastic states are entirely different, yet the failure strains differ by only about $15 \%$, these results suggest that the failure process at these strain rates depends at least partly upon something other than ductile to brittle transition in the plastic. It is interesting to note that FEA modeling of the microstructure (Figs. 5, 6 and 12) predicts regions of high stress in the matrix at the tips of fibers. Furthermore, at higher loads, this predicted stress is greater than the failure stress of the plastic suggesting that matrix stress concentrations in the composite play an important role in the failure process, and the fracture process possibly initiates due to these concentrations.

Fig. 15(a) is an SEM image of a specimen of the same fiber type (short) but with microcellular structure, tested at the same conditions as Fig. 14(b). In contrast to the solid specimen in Fig. 14(b), here a mix of brittleness and ductility is seen in the plastic. The highly microcellular region in the upper left corner of the image is largely brittle, suggesting that these regions transition to brittle fracture earlier than solid regions. The solid regions also lack fiber pull-outs, as described previously for Fig. 1. When Fig. 15(b) is compared to Fig. 14(b), all regions are clearly brittle fracture; however, less fiber appears in the microcellular fracture 
surface, possibly owing to grazing fractures promoted by the presence of microcells. It is apparent that the ductile-to-brittle transition generally occurs somewhere between the slower $(0.0005 / \mathrm{s})$ and faster $(0.025 / \mathrm{s})$ quasi-static strain rates.
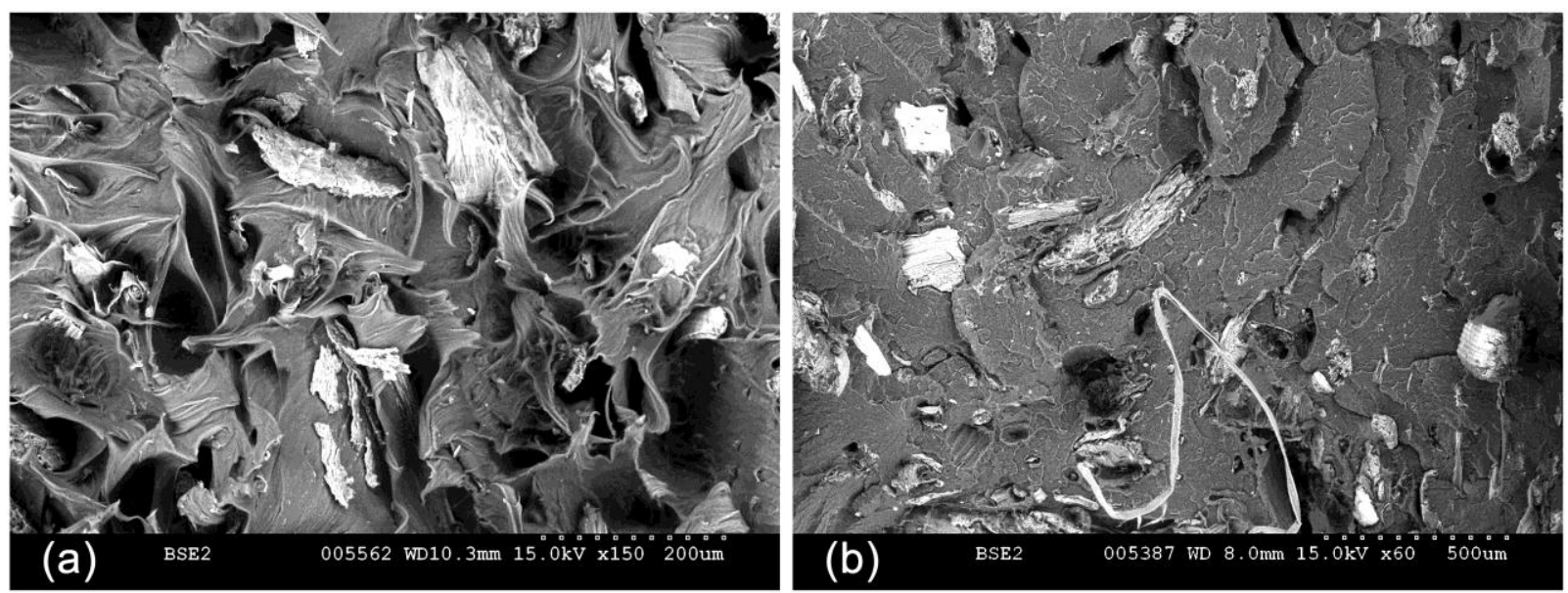

Fig. 14. (a) Ductile fracture surface of short-fiber, solid specimen at $0.0005 / \mathrm{s}, 22^{\circ} \mathrm{C}$; (b) Brittle fracture surface of short-fiber, solid specimen at $0.025 / \mathrm{s}, 22^{\circ} \mathrm{C}$. The lengths of fibers are between 150 and $300 \mu \mathrm{m}$.
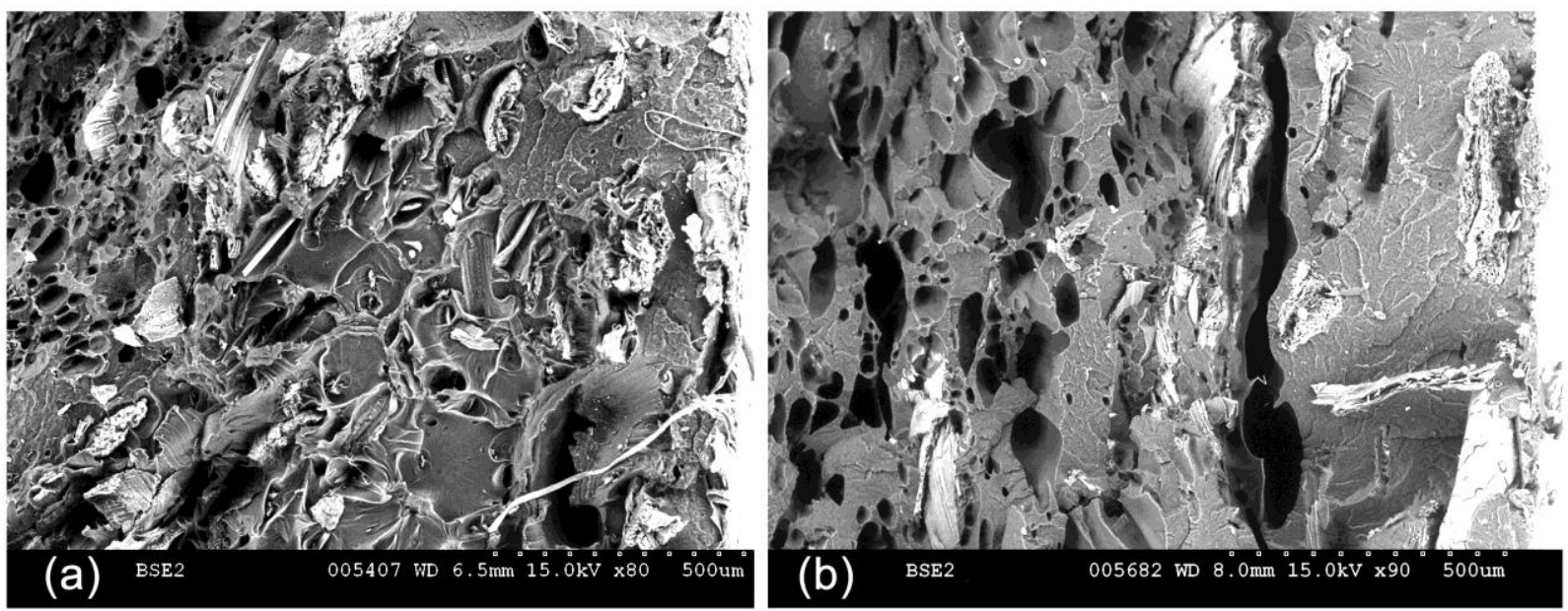

Fig. 15. Fracture of microcellular test specimens at $22^{\circ} \mathrm{C}, 0.025 / \mathrm{s}$ : (a) mixed-mode (brittle/ductile) fracture of a short-fiber (150-300 $\mu \mathrm{m})$ specimen, (b) brittle fracture of a longfiber $(650-1000 \mu \mathrm{m})$ specimen. 
Fig. 16 shows the SEM image of a microcellular, short fiber specimen tested at the highest rate, 14/s. In comparison to the lower rate specimen, Fig. 15(a), here the fracture surface is entirely brittle and fiber pull-out failures are less prevalent on the fracture surface, though evidence of fiber fractures is seen. These are identified by squared-off fiber ends, flush or nearlyflush with the fracture surface (Fig. 16(a), point P), and clearly-visible, open tubules in the fiber cross-section (Fig. 16(b)). Grazing fractures also remain evident in the microcellular regions. In the high rate case, tensile tests [32] show that higher stresses generally develop in the composite and this could partly account for the overall brittle appearance of the fracture surface and the presence of fiber failures in the microcellular regions, where they are not observed in lower rate tests.


Fig. 16. (a) Typical fracture surface of microcellular specimen tested at $14 / \mathrm{s}, 22^{\circ} \mathrm{C}$; (b) High magnification detail of an embedded fiber fracture.

\section{Conclusion}

The paper treats the microstructural behavior of solid and microcellular-voided composites of polypropylene with wheat straw reinforcing fibers using FEA modeling, mechanical test results and microscopy. The addition of wheat straw fiber to polypropylene has been found to enable microcellular foaming and is an economical, sustainable filler which does not compete with food supply, reduces environmental impact, and enhances end-of-life disposal options. Finite element models, scanning electron microscopy, and experimental stress-strain data appear to offer 
corollary explanations for the variations in elastic modulus, brittleness, and fiber stress found in the various cases. Interaction between fiber length effects and microcell effects appeared to reduce the effect of fiber length on the overall mechanical performance, confirmed by prior experimental testing on microcellular specimens.

\section{Acknowledgements}

This paper is based upon work supported by the National Science Foundation, USA, under grant number CMMI-1000307. The support is gratefully acknowledged. Any opinions, findings, and conclusions or recommendations expressed in this material are those of the authors and do not necessarily reflect the views of the National Science Foundation.

\section{References}

[1] Y. Li, Y.W. Mai, L. Ye, Sisal fibre and its composites: a review of recent developments, Composites Science and Technology, 60 (2000) 2037-2055.

[2] P. Roe, M.P. Ansell, Jute-reinforced polyester composites, Journal of Materials Science, 20 (1985) 4015-4020.

[3] A.K. Bledzki, O. Faruk, V.E. Sperber, Cars from Bio-Fibres, Macromolecular Materials and Engineering, 291 (2006) 449-457.

[4] N. Lucas, C. Bienaime, C. Belloy, M. Queneudec, F. Silvestre, J.-E. Nava-Saucedo, Polymer biodegradation: Mechanisms and estimation techniques-A review, Chemosphere, 73 (2008) 429-442.

[5] D. Rusu, S.A.E. Boyer, M.-F. Lacrampe, P. Krawczak, Bioplastics and Vegetal Fiber Reinforced Bioplastics for Automotive Applications, in: Handbook of Bioplastics and Biocomposites Engineering Applications, John Wiley \& Sons, Inc., 2011, pp. 397-449.

[6] N. Kengkhetkit, T. Amornsakchai, A new approach to "Greening” plastic composites using pineapple leaf waste for performance and cost effectiveness, Materials \& Design, 55 (2014) 292-299.

[7] F.C. Campbell, Structural Composite Materials, A.S.M. International, (2010) Ch. 10, Discontinuous-fiber composites.

[8] F. Zaïri, M. Naït-Abdelaziz, J. Gloaguen, A. Bouaziz, J.-M. Lefebvre, Micromechanical modelling and simulation of chopped random fiber reinforced polymer composites with 
progressive debonding damage, International Journal of Solids and Structures, 45 (2008) 5220-5236.

[9] J. Karger-Kocsis, K. Friedrich, Fracture behavior of injection-molded short and long glass fiber-polyamide 6.6 composites, Composites Science and Technology, 32 (1988) 293-325.

[10] E. Rodriguez, R. Petrucci, D. Puglia, J.M. Kenny, A. Vazquez, Characterization of composites based on natural and glass fibers obtained by vacuum infusion, Journal of Composite Materials, 39 (2005) 265-282.

[11] V.P. Arthanarieswaran, A. Kumaravel, M. Kathirselvam, Evaluation of mechanical properties of banana and sisal fiber reinforced epoxy composites: Influence of glass fiber hybridization, Materials \& Design, 64 (2014) 194-202.

[12] S. Rahmanian, A.R. Suraya, M.A. Shazed, R. Zahari, E.S. Zainudin, Mechanical characterization of epoxy composite with multiscale reinforcements: Carbon nanotubes and short carbon fibers, Materials \& Design, 60 (2014) 34-40.

[13] M.A. Al-Maadeed, Y.M. Shabana, P.N. Khanam, Processing, characterization and modeling of recycled polypropylene/glass fibre/wood flour composites, Materials \& Design, 58 (2014) 374-380.

[14] R. Satheesh Raja, K. Manisekar, V. Manikandan, Study on mechanical properties of fly ash impregnated glass fiber reinforced polymer composites using mixture design analysis, Materials \& Design, 55 (2014) 499-508.

[15] M.M. Shokrieh, A. Saeedi, M. Chitsazzadeh, Evaluating the effects of multi-walled carbon nanotubes on the mechanical properties of chopped strand mat/polyester composites, Materials \& Design, 56 (2014) 274-279.

[16] W. Kim, A. Argento, E. Lee, C. Flanigan, D. Houston, A. Harris, D.F. Mielewski, High strain-rate behavior of natural fiber-reinforced polymer composites, Journal of Composite Materials, 46 (2012) 1051-1065.

[17] A. Argento, W. Kim, E.C. Lee, A.M. Harris, D.F. Mielewski, Rate dependencies and energy absorption characteristics of nanoreinforced, biofiber, and microcellular polymer composites, Polymer Composites, 32 (2011) 1423-1429.

[18] A.K. Bledzki, O. Faruk, Microcellular injection molded wood fiber-PP composites: Part IIEffect of wood fiber length and content on cell morphology and physico-mechanical properties, Journal of Cellular Plastics, 42 (2006) 77-88. 
[19] I. Naghmouchi, F.X. Espinach, P. Mutjé, S. Boufi, Polypropylene composites based on lignocellulosic fillers: How the filler morphology affects the composite properties, Materials \& Design, 65 (2015) 454-461.

[20] W. Kim, A. Argento, Chapter 11. High strain rate testing of natural fiber composites, in: A. Hodzic, R. Shanks (Eds.) Natural Fibre Composites, Woodhead Publishing, 2014, pp. 303322.

[21] R. Yahaya, S.M. Sapuan, M. Jawaid, Z. Leman, E.S. Zainudin, Effect of layering sequence and chemical treatment on the mechanical properties of woven kenaf-aramid hybrid laminated composites, Materials \& Design, 67 (2015) 173-179.

[22] P. Zakikhani, R. Zahari, M.T.H. Sultan, D.L. Majid, Extraction and preparation of bamboo fibre-reinforced composites, Materials \& Design, 63 (2014) 820-828.

[23] A.K. Bledzki, O. Faruk, Injection moulded microcellular wood fibre-polypropylene composites, Composites Part A: applied science and manufacturing, 37 (2006) 1358-1367.

[24] A.K. Bledzki, O. Faruk, H. Kirschling, J. Kuhn, A. Jaszkiewicz, Microcellular polymers and composites. Part I. Types of foaming agents and technologies of microcellular processing, Polimery/Polymers, 51 (2006) 697-703.

[25] O. Faruk, A.K. Bledzki, Microcellular natural and wood fibre reinforced polymer composites, Natural fibre reinforced polymer composites: from macro to nanoscale, (2009).

[26] A.K. Bledzki, J. Kühn-Gajdzik, Microcellular of glass fibre reinforced PC/ABS: Effect of the processing condition on the morphology and mechanical properties, Cellular Polymers, 29 (2010) 27-43.

[27] O. Faruk, A.K. Bledzki, Microcellular injection molded wood fiber-PP composites: Part I Effect of chemical foaming agent content on cell morphology and physico-mechanical properties, Journal of Cellular Plastics, 42 (2006) 63-76.

[28] S. Leicher, J. Will, H. Haugen, E. Wintermantel, MuCell [registered trademark] technology for injection molding: A processing method for polyether-urethane scaffolds, Journal of Materials Science, 40 (2005) 4613-4618.

[29] N. Bonora, A. Ruggiero, Micromechanical modeling of composites with mechanical interface - Part 1: Unit cell model development and manufacturing process effects, Composites Science and Technology: Experimental Techniques and Design in Composite Materials, 66 (2006) 314-322. 
[30] N. Jarvstrat, An ellipsoidal unit cell for the calculation of micro-stresses in short fibre composites, in: International Workshop on FE-Modelling of the Mechanical Behavior of Materials, 26-27 Oct. 1992, Netherlands, 1993, pp. 203-212.

[31] J. Van Dommelen, W. Brekelmans, F. Baaijens, Micromechanical modeling of particletoughening of polymers by locally induced anisotropy, Mechanics of Materials, 35 (2003) 845-863.

[32] W.T. Kern, W. Kim, A. Argento, E. Lee, D.F. Mielewski, Mechanical behavior of microcellular, natural fiber reinforced composites at various strain rates and temperatures, Polymer Testing, 37 (2014) 148-155.

[33] N. Petchwattana, S. Covavisaruch, Influences of particle sizes and contents of chemical blowing agents on foaming wood plastic composites prepared from poly(vinyl chloride) and rice hull, Materials \& Design, 32 (2011) 2844-2850.

[34] D. Jahani, A. Ameli, P.U. Jung, M.R. Barzegari, C.B. Park, H. Naguib, Open-cell cavityintegrated injection-molded acoustic polypropylene foams, Materials \& Design, 53 (2014) 20-28.

[35] M. Rodriguez-Perez, J. Lobos, C. Perez-Muñoz, J. de Saja, Mechanical response of polyethylene foams with high densities and cell sizes in the microcellular range, Journal of Cellular Plastics, 45 (2009) 389.

[36] P. Hornsby, E. Hinrichsen, K. Tarverdi, Preparation and properties of polypropylene composites reinforced with wheat and flax straw fibres: part I fibre characterization, Journal of Materials Science, 32 (1997) 443-449.

[37] S. Panthapulakkal, A. Zereshkian, M. Sain, Preparation and characterization of wheat straw fibers for reinforcing application in injection molded thermoplastic composites, Bioresource Technology, 97 (2006) 265-272.

[38] M. Sain, S. Panthapulakkal, Bioprocess preparation of wheat straw fibers and their characterization, Industrial Crops and Products, 23 (2006) 1-8.

[39] W. McKean, R. Jacobs, Wheat Straw as a Paper Fiber Source, Washington USA: Clean Washington Center, (1997).

[40] M. Hbib, S. Guessasma, D. Bassir, N. Benseddiq, Interfacial damage in biopolymer composites reinforced using hemp fibres: Finite element simulation and experimental investigation, Composites Science and Technology, 71 (2011) 1419-1426. 
[41] M. Kamiński, B. Lauke, Probabilistic effective characteristics of polymers containing rubber particles of Gaussian random diameter, Composite Structures, 135 (2016) 397-408.

[42] H. Fukuda, K. Kawata, Stress and strain fields in short fibre-reinforced composites, Fibre Science and Technology, 7 (1974) 129-156.

[43] P. Hancock, R. Cuthbertson, The effect of fibre length and interfacial bond in glass fibreepoxy resin composites, Journal of Materials Science, 5 (1970) 762-768.

[44] C. Chou, K. Vijayan, D. Kirby, A. Hiltner, E. Baer, Ductile-to-brittle transition of rubbermodified polypropylene Part II, Journal of Materials Science, 23 (1988) 2533-2545.

[45] A. Demsey, R.L. Steere, W.E. Brandt, B.J. Veltri, Morphology and development of dengue2 virus employing the freeze-fracture and thin-section techniques, Journal of Ultrastructure Research, 46 (1974) 103-116.

[46] C. Barry, Why glass sometimes breaks, in: Photovoltaic Specialists Conference (PVSC), 2009 34th IEEE, 2009, pp. 002144-002149.

[47] T.L. Anderson, Fracture mechanics: fundamentals and applications, CRC press, 2005.

[48] S. Wang, Q. Cheng, T.G. Rials, S.-H. Lee, Cellulose microfibril/nanofibril and its nanocompsites, in: Proceedings of the 8th Pacific Rim Bio-Based Composites Symposium, 2006, pp. 301-308.

[49] B.A. Acha, M.M. Reboredo, N.E. Marcovich, Creep and dynamic mechanical behavior of PP-jute composites: Effect of the interfacial adhesion, Composites Part A: applied science and manufacturing, 38 (2007) 1507-1516.

[50] S. Mohanty, S.K. Verma, S.K. Nayak, Dynamic mechanical and thermal properties of MAPE treated jute/HDPE composites, Composites Science and Technology, 66 (2006) 538547.

[51] J. Biagiotti, S. Fiori, L. Torre, M. López-Manchado, J.M. Kenny, Mechanical properties of polypropylene matrix composites reinforced with natural fibers: a statistical approach, Polymer Composites, 25 (2004) 26-36. 
Wheat-straw-fiber/polypropylene composites under tensile loading

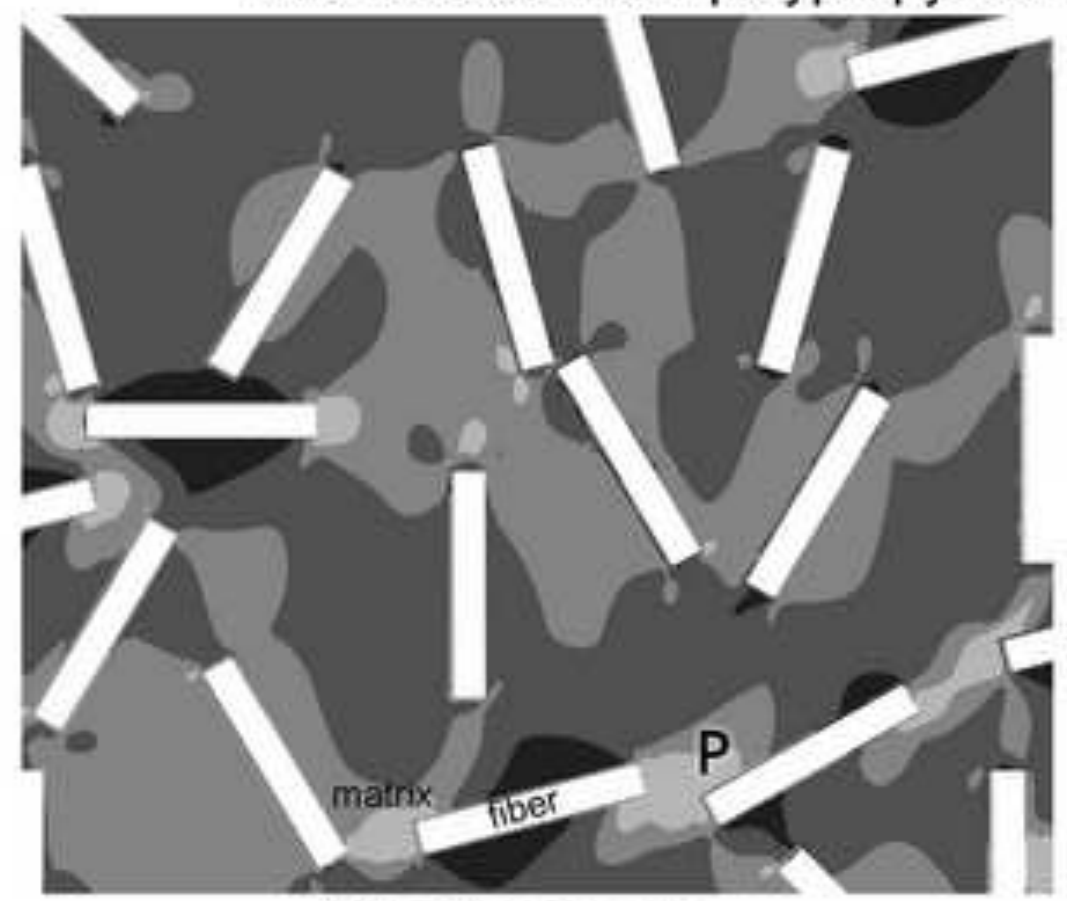

Without microcells

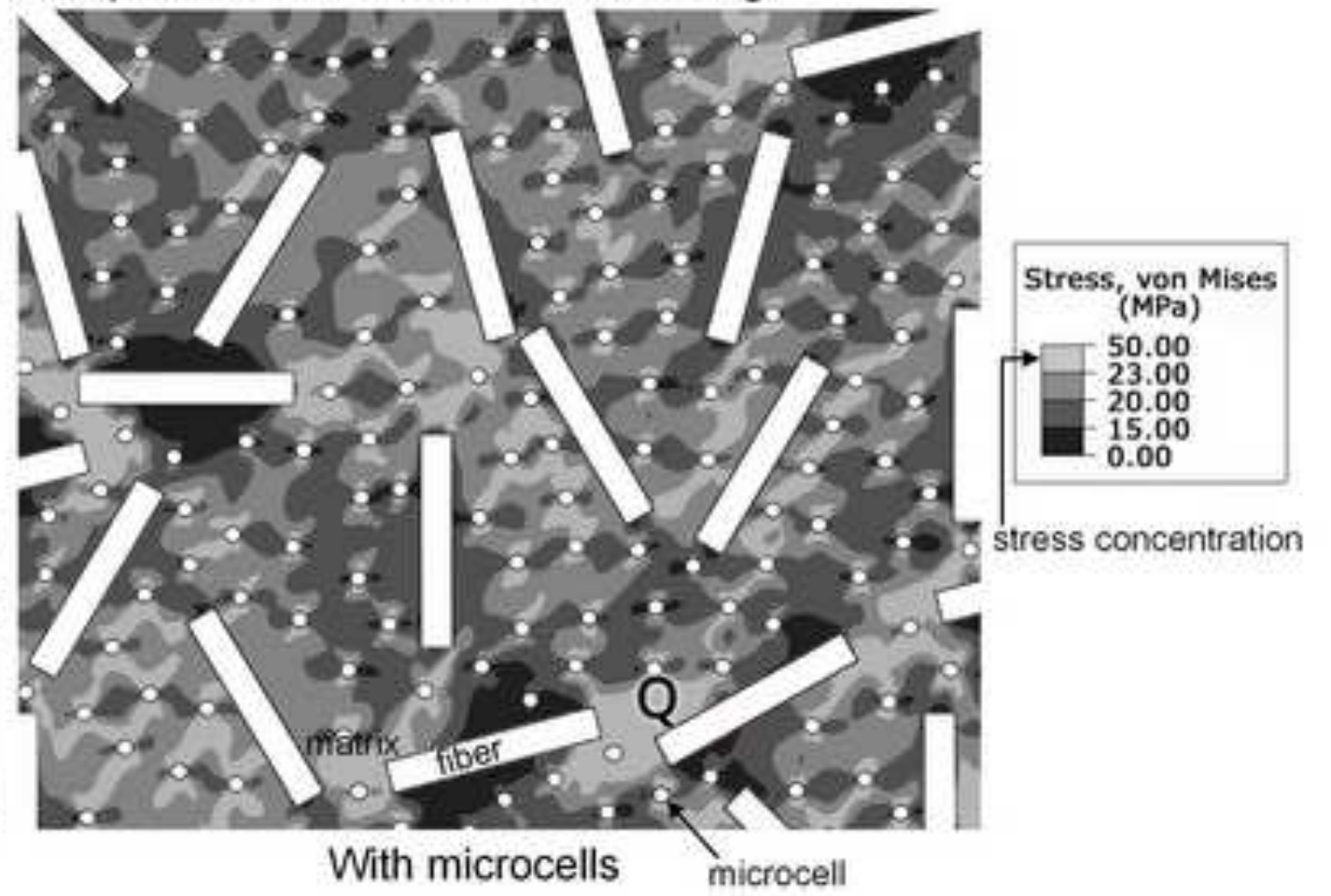

